\title{
Live Architecture: Venues, Stages and Arenas for Popular Music
}

\author{
Robert Kronenburg \\ London and New York: Routledge, 2012 \\ ISBN: $9780415561921(\mathrm{HB})$
}

\author{
Eduardo Viñuela \\ University of Oviedo, Spain \\ eduvisu@gmail.com
}

In the study of popular music concerts it is easy to find works that approach gigs as some kinds of ritual practices and venues as social constructed spaces and also as places where there is a hierarchical stratification of audiences. But it is not that common to find studies that focus on the architecture of these spaces and how it affects our perception of live music. This is the scope Robert Kronenburg studies in his book, analyzing the design and the structure of different kinds of spaces for live popular music, paying attention to acoustics, security, and functionality. He argues that performance spaces are in constant renovation, aiming to create adequate structures to improve the experience of live music. Thus it is possible to approach these architectures from a historical perspective, analysing the architectural form of several cases from different countries and periods by considering the objectives and the dimensions of each construction.

The book is conceived as a case-studies compilation, organised in four chapters, each of which establishes a typology of constructions (adopted spaces, adapted spaces, dedicated spaces and mobile spaces) which are proposed and explained by the author in the introduction and in the beginning of each section. The first typology considers adopted spaces, "the easiest and most common platform for performance" (2012:15) as well as the oldest in history, since quite often these places are local bars that host concerts from time to time. Kronenburg analyses the cases of legendary clubs such as the 100 Club in London and Birdland in New York. Both of them are bars with a large tradition in performance that made music their main activity and so they became a point of reference in the local music scene. Birdland is a key club to understand the jazz scene of New York and 100 Club hosts the artists of London's local music scene since the 1940s and therefore is the place for different genres ever since: swing, jazz, beat, punk, Brit pop.

The second typology deals with adapted spaces, a category very close to the previous one. As the author states, "the line between adopted and adapted spaces is not fixed" (2012: 40), sometimes the former can even be considered adapted when there is some kind of alteration in the construction. There are many examples that can be included in this category, since it is a common strategy to convert huge abandoned buildings (quite often situated in industrial areas) in multifunctional art centers that regularly include auditoriums or other performance spaces. Among the buildings that 
Kronenburg includes here, such as the $\mathrm{O} 2$ arena in Dublin or the High Line Ballroom in New York, the VIP in Saint-Nazaire (France) is an example of this kind of urban interventions to regenerate an industrial area; the original building was a massive bunker used by the Nazis in the 1940s as a submarine base. During the 1990s, a regeneration project started in the city affected this building that finally opened in 2007 as a venue for contemporary music. Kronenburg states that this kind of intervention "brings local people to the space for something different, and creates new memories to layer over the old ones" (55).

The larger chapter is devoted to dedicated spaces, in particular those that have been built specifically to serve as concert venues. This third typology is the ideal one, because it allows planning everything in the building from the very beginning. Yet, at the same time, the enormous investments required for these projects make them an economic risk. Thus, many of these buildings are conceived as multifunctional spaces that can host different activities and be adapted for many utilities. In this category, the author focuses mainly on large venues, such as The Colosseum in Las Vegas and The Grand Ole Opry House in Nashville (USA), as well as on small places such as De Vorstin in Hilversum (the Netherlands). It is worth noting two case studies that are located in the city of Liverpool: one small, The Cavern, and one huge, The Echo Arena, each paradigmatic of two different periods in the city. Kronenburg focuses on the history of The Cavern as one of the key clubs to understand Merseybeat sound during the 1960s, adding to this a study of changes to the club until the present day and its contemporary varied functions, both as a tourist attraction and as an active music club with around 40 concerts each week. If The Cavern is the symbol of a time when Liverpool was an important port, The Liverpool Echo Arena, opened in 2007, symbolises the urban regeneration project (after decades of industrial crisis) that took place in the last few years, supported by the designation of the city as European Capital of Culture in 2008.

The final chapter is dedicated to the fourth typology: mobile spaces, an eclectic category where Kronenburg includes all sorts of portable buildings and stages for concerts, for example, in public parks, at festivals or on tour stages. These are flexible structures that are easily adapted to the requirements of each activity, such as the modular principle in the design of The Valhalla in 2000 and the architecture of festivals, that allow building a city in a few weeks (191). Although all of these are ephemeral, "they do create a permanent presence in the memory of those who take part both as performer and audience member" (153).

This book is richly illustrated with design drawings, floor plans and full colour photographs of each case study. Robert Kronenburg is an architect with an interest in popular music, which inspired him to visit numerous architectural designs of concert settings since 2008. Still, even if there is a significant effort towards an interdisciplinary approach, the resulting analysis is sometimes too descriptive and there is a lack of references to the abundant literature on popular music and urban spaces. This would have helped to delve deeper into the definition of the typologies and to explore the social significance of live music architectures. Nevertheless, this book is a great contribution to a field of study that is still developing, offering a useful tool to establish bridges between architecture and popular music studies. 